\title{
Tonsillektomi yapılan erişkin hastalarda dil basacağına bağlı ortaya çıkan dil ödeminin ultrasonografi ile değerlendirilmesi: Prospektif, paralel grup, klinik çalışma
}

\section{Evaluation of postoperative tongue edema with ultrasonography due to tongue depressor in adult patients undergoing tonsillectomy: A prospective, parallel-group, clinical study}

\author{
Çă̆daş Elsürer ${ }^{1}$
}

${ }^{1}$ Selcuk Üniversitesi Tıp Fakültesi, Kulak Burun Boğaz AD, Konya, Türkiye

$\ddot{O} \mathbf{z}$

Amaç: Tonsillektomi cerrahisi, Kulak Burun Boğaz (KBB) pratiğinde en sık yapılan cerrahi işlemlerden biridir. Ameliyat sırasında cerrahın görüş alanını arttırmak için kullanılan ağız açacağı ve dil basacağı, hastanın dil dokusuna yüksek basınç uygulayarak çeşitli komplikasyonlara neden olabilir. Bu çalışmanın amacı, tonsillektomi yapılan erişkin hastalarda, cerrahi esnasında kullanılan dil basacağının dil üzerinde oluşturduğu basınca bağlı olarak gelişmesi muhtemel dil ödeminin, ultrasonografi (USG) ile araştırılmasıdır.

\begin{abstract}
Gereç ve yöntem: Çalışmaya 18-40 yaş arası hastalar dahil edildi ve iki gruba ayrıldı. Çalışma grubu ( $\mathrm{n}=31)$, KBB kliniğinde tonsillektomi yapılan hastalardan oluşmakta iken kontrol grubu (n =30), genel anestezi altında tonsillektomi dışında başka bir cerrahi yapılan, dil dokusuna herhangi bir baskı uygulanmayan ve genel anestezi süresi, tonsillektomi cerrahisinin süresine yakın olan hastalardan olușturuldu. Her hastanın, submental koronal plan Ultrasonografi (USG) ile dil kesit alanı (TA) iki defa ölçüldü. Çalıșma grubunda ilk ölçüm (TA1) endotrakeal entübasyondan hemen sonra, ancak ağız açacağı ve dil basacağı takılmadan önce yapıldı. İkinci ölçüm, (TA2) tonsillektomi cerrahisinin sonunda, dil basacağı çıartıldıktan sonra ancak ekstübasyondan hemen önce yapıldı. Kontrol grubunda, ilk ölçüm (TA1) endotrakeal entübasyondan hemen sonra, ikinci ölçüm (TA2) ise, cerrahi bitiminde ancak ekstübasyondan hemen önce yapıldı. Dil ödemi, dil kesit alanları farkı (TA2 - TA1) olarak tanımlandı. Gruplar dil kesit alanları açısından ve dil ödemi açısından karșılaștırıldı.
\end{abstract}

Bulgular: Gruplar arasında, demografik açıdan ve genel anestezi süreleri açısından fark yoktu. TA1 değerleri bakımından, tonsillektomi $(3.93 \pm 1.29 \mathrm{~cm} 2)$ ve kontrol grupları $(3.80 \pm 1.20 \mathrm{~cm} 2)$ arasında anlamlı bir fark bulunmadı $(\mathrm{p}=0.212)$. TA2 değerleri bakımından, tonsillektomi grubu $(4.63 \pm 0.28 \mathrm{~cm} 2)$ ile kontrol grubu $(3.91 \pm 0.23 \mathrm{~cm} 2)$ arasında anlamlı fark bulundu $(\mathrm{p}=0.000)$. Tonsillektomi grubu dil ödemi değerleri $(0.90 \pm 0.26 \mathrm{~cm} 2)$, kontrol grubu değerlerine $(0.11 \pm 0.07 \mathrm{~cm} 2)$ göre yüksek bulundu $(p=0.000)$.

Sonuç: Çalıșmamız ile, erișkin hastalarda gerçekleștirilen tonsillektomi cerrahisinde kullanılan ağız açacağı ve dil basacağının dil üzerinde olușturduğu yüksek basınca bağlı olarak dil ödemi gelişmiş ve dil ödemi USG ile tespit edilmiştir.

Anahtar Kelimeler: tonsillektomi; komplikasyonlar; ultrasonografi; tanısal görüntüleme

Abstract

Objective: Tonsillectomy is one of the most common surgical procedures performed in Ear Nose Throat (ENT) practice. The tongue depressor, which is routinely used during tonsillectomy surgeries, may cause various complications by applying high pressure to the patient>s tongue. In this study, we aimed to investigate the tongue edema caused by the pressure applied by the tongue depressor using ultrasonography (USG) in adult patients who underwent tonsillectomy.

Material and Methods: Our study consisted of two groups, including patients between the ages of 18-40. The patients in the study group ( $\mathrm{n}=31$ ) were composed of patients who underwent tonsillectomy surgeries in the ENT clinic. The patients in the control group $(\mathrm{n}=30)$ were composed of patients who were operated on for a reason other than tonsillectomy under general anesthesia, no pressure was applied on the tongue during surgery, and the duration of general anesthesia was close to the duration of tonsillectomy surgeries. Submental coronal plane USG examination of the tongue area (TA) was performed twice for each patient. The first tongue area examination (TA1) was performed immediately after intubation but before inserting the tongue depressor in the tonsillectomy group. The second tongue area examination (TA2) was performed at the end of the tonsillectomy surgery, after removal of the tongue depressor just before extubation. In the control group, the first tongue area examination (TA1) was performed immediately after intubation, and the second tongue area examination (TA2) was performed at the end of the operation just before extubation. Tongue edema, which is thought to occur due to the high pressure applied by the tongue depressor during tonsillectomy surgeries, was calculated by the difference in tongue areas (i.e., TA2 - TA1).

Results: The groups were similar in terms of demographic data and general anesthesia duration. When the mean TA1 values were taken into account between the tonsillectomy ( $3.93 \pm 1.29 \mathrm{~cm} 2)$ and control $(3.80 \pm 1.20 \mathrm{~cm} 2)$ groups, no significant difference was found $(\mathrm{p}=0.212)$. The mean TA2 value of the tonsillectomy group $(4.63 \pm 0.28 \mathrm{~cm} 2)$ was greater than the control group's TA2 value $(3.91 \pm 0.23 \mathrm{~cm} 2)$ and was significantly different $(\mathrm{p}=0.000)$. In addition, the mean tongue edema value of the tonsillectomy group $(0.90 \pm 0.26 \mathrm{~cm} 2)$ was greater than the control group $(0.11$ $\pm 0.07 \mathrm{~cm} 2)$ and was significantly different $(\mathrm{p}=0.000)$.

Conclusion: The tongue depressor used caused tongue edema in tonsillectomy surgeries in adult patients. This tongue edema appears to be the result of the pressure exerted by the tongue depressor. This study is the first to show the possible role of USG in determining tongue edema due to tongue depressor in adult patients undergoing tonsillectomy.

Keywords: tonsillectomy; complications; ultrasonography; diagnostic imaging

Yazışma Adresi: Çağdaş Elsürer, Selçuk Üniversitesi Tıp Fakültesi, Kulak Burun Boğaz AD, Konya, Turkiye

E-Posta: cagdaselsurer@yahoo.com

Alınma Tarihi: 20.08.2021 / Kabul Tarihi: 31.08.2021 / Yayımlanma Tarihi: 20.09.2021

Postoperatif dil ödeminin ultrasonografí ile değerlendirilmesi - Elsürer

Genel Tip Derg 2021;31(3)304-308 
Ultrasonografi (USG), tendonlar, kaslar, eklemler, damarlar ve iç organlar gibi birçok yapıyı değerlendirmek için ses dalgalarının kullanıldığı görüntüleme yöntemidir $(1,2)$. USG, gerçek zamanlı görüntüleri, ucuz, non-invaziv ve radyasyon salınımı yapmadan sağladığından, klinisyen ve hasta için diğer görüntüleme yöntemlerine göre daha avantajlıdır $(1,3)$.

Dil, ağız boşluğunda yer alan ve birçok kas grubunun oluşturduğu bir organdır. Dil kasları yapısal olarak iskelet kaslarına benzer (2). Fizik muayene ile herhangi bir görüntüleme yöntemi kullanılmadan çıplak gözle değerlendirilebilir (4). Ancak, çoğunlukla kaslardan oluştuğu için, detaylı inceleme USG ile yapılabilmektedir $(2,5,6)$. USG ile dilin kalınlığı, kesit alanı, dilin damar yapıları, dil dokusuna ait yapılar ve dildeki lezyonlar ortaya konabilir $(1,2,7)$. USG ile dil muayenesi, USG probunun ağız içine yerleştirilmesiyle yapılabilmekle birlikte (8), submental bölgeye yerleştirilen prob ile daha kolay, hızlı ve hasta ile uyumlu bir şekilde yapılabilmektedir $(2,6)$.

Tonsillektomi cerrahisi, tüm Dünya'da Kulak Burun Boğaz (KBB) klinisyenlerinin en çok yaptığı ameliyatlardan biridir. Tonsillektomi esnasında, ağız boşluğunu açmak ve dil dokusunu ameliyat alanının dışında tutmak için ağız açacağ1 ve dil basacağı kullanılır. Ağız açacağının boyutu standart olmakla birlikte dil basacağının boyutu ağız boşluğunun boyutuna bağlı olarak yetişkin veya pediatrik hastalarda değişkenlik göstermektedir. Tonsillektomi esnasında, hemen her zaman klinisyenler tonsil dokusunu görmek için dil basacağını kullanır ve dile baskı uygulayarak dilin görüş alanından çıkmasını sağlar. Tonsillektomi cerrahisi tamamlanana kadar dil basacağı, dil üzerinde basınç oluşturur. Literatürde, bazı olgu sunumlarında, dil basacağının dil üzerinde oluşturduğu yüksek basınç nedeniyle bazı hastalarda masif dil ödemi geliştiği bildirilmiştir $(9,10)$. Ayrıca ekstübasyondan hemen sonra fark edilemeyen, ortaya çıkışı ekstübasyondan sonraki ikinci saat ile 24 saat arasında değişen, hava yolu obstrüksiyonuna yol açabilen mekanik nedenlere bağlı dil ödeminin gelişimi ve tanısı ile ilgili çalışmalar yapılmıştır. Çocuk hastalarda yapılan tonsillektomi ve adenoidektomi ameliyatlarında kullanılan ağız açacağı ve dil basacağına bağlı ortaya çıkan dil ödemi ve erişkin hastalarda yapılan süspansiyon laringoskopi işlemi esnasında kullanılan süspansiyon kaşığına bağlı olarak ortaya çıkan dil ödemi daha önce USG ile tespit edilmiştir $(2,11,12)$. Ancak erişkin hastalarda yapılan tonsillektomi esnasında kullanılan ağız açacağı ve dil basacağının dil üzerinde oluşturduğu basınca bağlı olarak gelişmesi muhtemel dil ödeminin tespiti ile ilgili herhangi bir çalışma yapılmamıştır.

Hipotezimiz, erişkin hastalarda, tonsillektomi cerrahisinde, klinisyen tarafından kullanılan dil basacağının dil üzerinde oluşturduğu basınca bağlı olarak, dil ödemi gelişeceği ve dil ödeminin USG ile tespit edilebileceğiydi.

\section{Materyal- Metod}

\section{Çalışmanın dizaynı}

Bu çalışma, Selçuk Üniversitesi Tıp Fakültesi Girişimsel Olmayan Etik Kurulu tarafından onaylanmıştır (2018/336). Bu klinik çalışma prospektif, gözlemsel ve paralel grup olarak tasarlanmıştır.

Çalışma grupları
Çalışmamız 18-40 yaş arası hastaların dahil edildiği iki gruptan oluşmaktadır. Çalışmaya dahil edilen tüm hastalardan onam alındı. Tonsillektomi grubu $(\mathrm{n}=31) \mathrm{KBB}$ kliniğinde tonsillektomi cerrahisi yapilan hastalardan, kontrol grubu $(\mathrm{n}=30)$ genel anestezi altında endotrakeal entübasyon işlemi uygulandıktan sonra tonsillektomi cerrahisi dışında başka bir neden ile opere edilen hastalardan oluşturuldu. Kontrol grubundaki hastaların genel anestezi aldıkları süre, tonsillektomi cerrahisinin süresine yakındı ve dil dokuları üzerine basınç uygulanmadı. Çalışmaya dahil edilmeme kriterleri; (i) çalışmaya katılmayı reddetmek; (ii) $<18$ yaşında olmak; (iii) sendromik kraniyofasiyal anormalliklerin varlığı (yani, Down sendromu vs.); (iv) dil üzerinde kitle varlığı; (v) kraniyofasiyal cerrahi geçmişi; (vi) baş ve boyun yanığı, travma veya radyoterapi öyküsü; (vii) nörolojik bozukluklar ve obstrüktif uyku apne sendromu (OUAS) olanlar; (viii) baş ve boyun bölgesinde akut inflamasyon; veya (ix) boyun fleksiyonunu ve başın ekstansiyonunu sınırlayan servikal sertlik.

\section{Ölçümler}

Tonsillektomi grubundaki hastalara, submental USG ile yapılan ilk dil kesit alanı ölçümü (TA ${ }^{1}$ ), endotrakeal entübasyondan hemen sonra, ancak dil basacağı ağız içine yerleştirilmeden önce yapıldı (Resim 1). İkinci dil kesit alanı ölçümü $\left(\mathrm{TA}^{2}\right)$, tonsillektomi cerrahisi tamamlandıktan ve dil basacağı ağızdan çıkartıldıktan sonra, ancak hasta ekstübe edilmeden hemen önce yapıldı (Resim 2). Kontrol grubundaki hastalara submental USG ile yapılan ilk dil kesit alanı ölçümü (TA ${ }^{1}$ ), endotrakeal entübasyondan hemen sonra yapıldı. İkinci dil kesit alanı ölçümü $\left(\mathrm{TA}^{2}\right)$, cerrahi işlem tamamlandıktan sonra ancak hasta ekstübe edilmeden hemen önce yapıldı. Dil ödemi, her iki grup için $\mathrm{TA}^{2}$ ve $\mathrm{TA}^{1}$ arasındaki fark olarak tanımlandı (yani $\left.\mathrm{TA}^{2}-\mathrm{TA}^{1}\right)$.

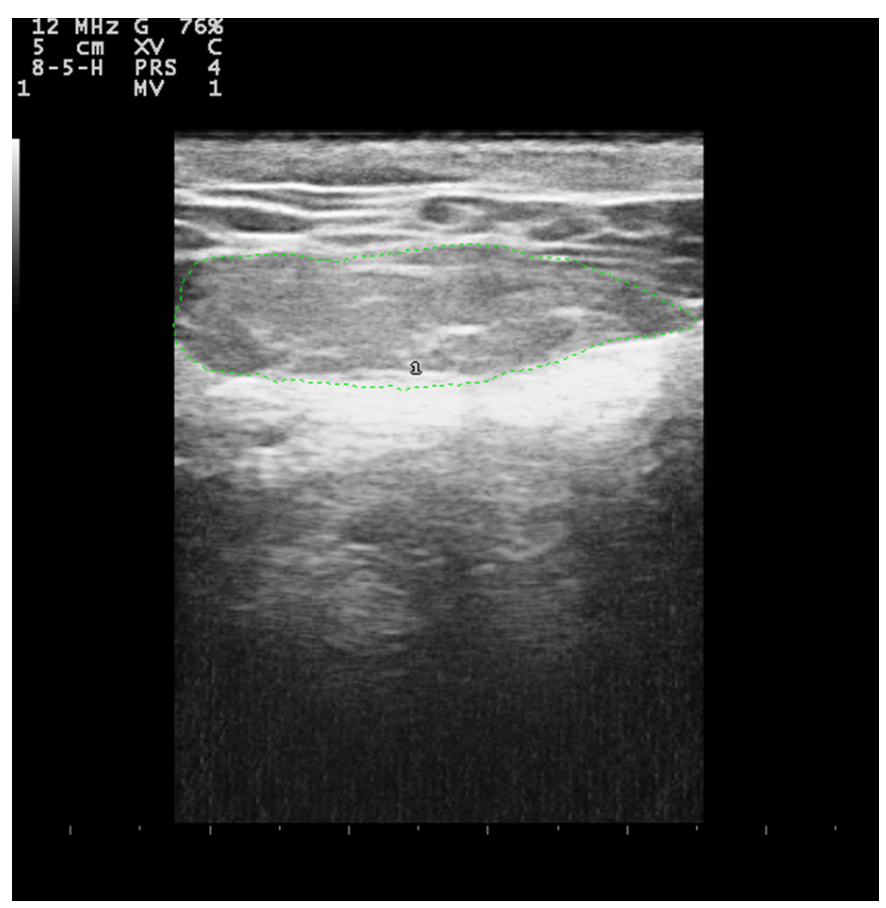

Resim 1. Endotrakeal entübasyondan sonra, dil basacağı ağız içine yerleştirilmeden hemen önce yapılan dil kesit alanı ölçümü. 


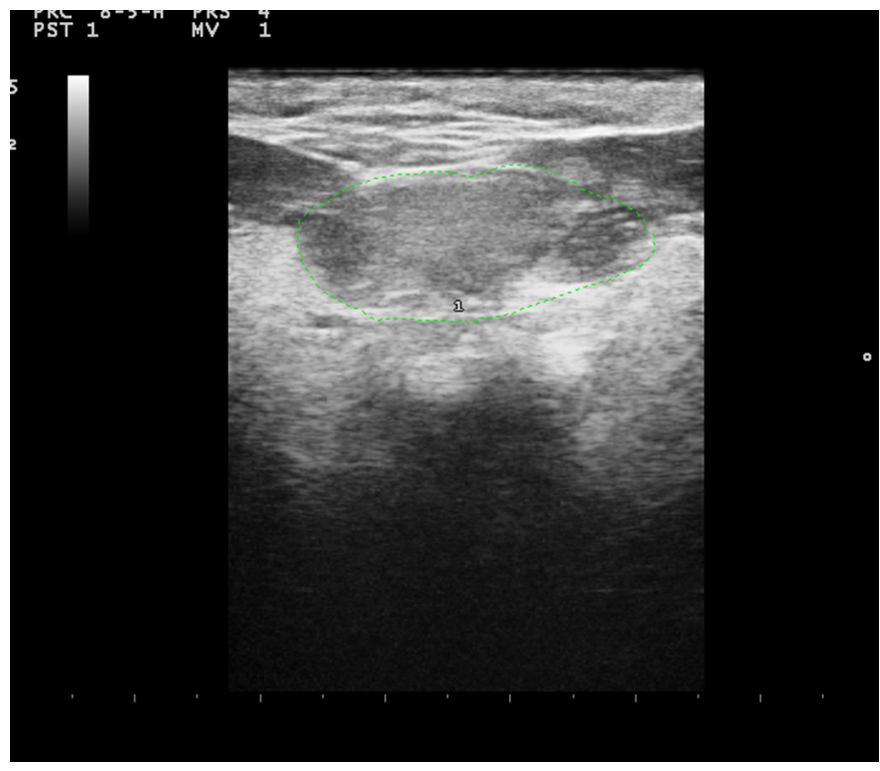

Resim 2. Tonsillektomi cerrahisi bittikten ve dil basacağı ağızdan çıkartıldıktan sonra, ekstübasyondan hemen önce yapılan dil kesit alanı ölçümü.

\section{Ultrasonografi ile dil kesit alanı ölçümü}

Dil kesit alanı ölçümü için $4 \mathrm{MHz}$ frekansında çalışan dışbükey problu Mindray DC60 USG (Çin) kullanıldı. Dil kesit alanı değerlendirmeleri, submental orta hat bölgesinin koronal düzleminden $4 \mathrm{MHz}$ eğimli dizilim ile yapıldı. Hasta supin pozisyonunda iken prob çene altına yerleştirildi ve dil görüntüsü alındığında proba fazla bastırmadan tüm dil kesit alanının monitörde görülebileceği şekilde ayarlandı. Dil tamamen görüntülendiğinde görüntü donduruldu ve dil kesit alanı otomatik olarak hesaplandı. Dil kesit alanı ölçümleri, submental USG ile dil değerlendirilmesi açısından bir pediatrik radyolog tarafından eğitilmiş ve en az 20 ölçüm yapmış olan aynı deneyimli anestezist tarafından, her hasta için iki kez yapıldı. Her ölçüm için en az üç ölçüm alındı ve her ölçümün analizinde bu ölçümlerin ortalaması kullanıld1.

\section{Tonsillektomi prosedürü}

Tüm tonsillektomi ameliyatları, genel anestezi altında aynı cerrah tarafından diseksiyon yöntemi ile yapıldı. Aynı boyutta Crowe-Davis ağız açacağı kullanılarak soğuk aletlerle tonsillektomi yapıldı ve bipolar diatermi ile hemostaz sağlandı. Anestezi indüksiyonu için tüm hastalara intravenöz metilprednizolon ( $1 \mathrm{mg} / \mathrm{kg}$ ) (Prednol-1, Mustafa Nevzat, İstanbul, Türkiye) uygulandı. Her hasta yaşına uygun aynı marka endotrakeal tüp ile entübe edildi ve endotrakeal tüp ağız ortasına sabitlendi. Ağız açacağı ile birlikte konulan dil basacağı, tonsillektomi tamamlanana kadar hastanın ağzına yerleştirildi ve bu süre kaydedildi. Tonsillektomi ameliyatı tamamlanmadan dil basacağının çıkartılması veya gevşetilmesi gereken hastalar çalışma dışı bırakıldı.

İstatistiksel analiz

Tüm veriler ortalama \pm standart sapma $(\mathrm{SD})$ olarak ifade edildi. Tonsillektomi ve kontrol grubu'ndaki hastaların her bir değişkene göre farklılık gösterip göstermediğini belirlemek için parametrik olmayan Mann-Whitney U testi kullanıldı. Veri analizi, Statistical
Package for the Social Science yazılım programı (SPSS Sürüm 17.0, IBM, Armonk, NY, ABD) kullanılarak yapıldı. $P<0.05$ değeri istatistiksel anlamlılığı gösterdi. Çalışmanın örneklem büyüklügünü hesaplamak için, çalışmaya başlamadan önce tonsillektomi cerrahisi yapılan 10 hasta ile bir pilot çalışma yapıldı. Pilot çalışmada, dil basacağ 1 yerleştirilmeden önce ve yerleştirildikten sonra dil kesit alanı değerlendirmeleri sırasıyla $3.95 \pm 0.29 \mathrm{~cm}^{2}$ ve $4.63 \pm 0.22 \mathrm{~cm}^{2}$ idi. SD' nin eşit olduğu varsayılarak ve 2 grup arasında \%20>lik bir fark ortaya çıkarmak için 0,05 >lik 2 taraflı tip I hatası ve $0.95^{\prime}$ lik bir güç uygulanarak, her grupta en az 16 hastaya ihtiyaç olduğu hesaplandı. Olası veri kayıpları göz önüne alınarak toplam 61 hasta çalışmamıza dahil edildi.

\section{Bulgular}

Demografik özellikler açısından tonsillektomi ve kontrol grupları arasında fark yoktu (Tablo 1). Hastaların ortalama genel anestezi süreleri açısından tonsillektomi (68.2 dakika) ve kontrol grubu (75.1 dakika) arasında anlamlı fark yoktu $(p=0.6)$. Ortalama $\mathrm{TA}^{1}$ değerleri karşılaştırıldığında, tonsillektomi $\left(3.93 \pm 0.29 \mathrm{~cm}^{2}\right)$ ve kontrol grupları $\left(3.80 \pm 0.20 \mathrm{~cm}^{2}\right)$ arasında anlaml fark bulunmadı $(p=0.212)$. TA ${ }^{2}$ değerleri karşılaştırıldığında, tonsillektomi grubunun ortalama $\mathrm{TA}^{2}$ değeri $\left(4.63 \pm 0.28 \mathrm{~cm}^{2}\right)$, kontrol grubunun ortalama $\mathrm{TA}^{2}$ değerinden $\left(3.91 \pm 0.23 \mathrm{~cm}^{2}\right)$ daha yüksekti ve anlamlı olarak farklıydı $(p=$ 0.000). Ayrıca, hesaplanan dil ödemi değerleri karşılaştırıldığında, tonsillektomi grubu $\left(0,73 \pm 0,26 \mathrm{~cm}^{2}\right)$ ile kontrol grubu $(0.11 \pm 0.07$ $\left.\mathrm{cm}^{2}\right)$ arasinda istatistiksel olarak anlaml fark bulundu $(p=0.000)$ (Tablo 2) (Şekil 2).

Tablo 1. Tonsillektomi ve kontrol grupları arasındaki tanımlayıcı istatistiklerin karşılaştırılması.

\begin{tabular}{|c|c|c|c|c|c|c|c|c|c|}
\hline & \multicolumn{4}{|c|}{ Tonsillektomi grubu $(\mathrm{n}=31)$} & \multicolumn{4}{|c|}{ Kontrol grubu $(\mathrm{n}=30)$} & \multirow[t]{2}{*}{$\mathbf{p}$} \\
\hline & Mean & SD & Min. & Max. & Mean & SD & Min. & Max. & \\
\hline Yaş (yll) & 33.94 & 6.14 & 28.50 & 43.02 & 34.91 & 7.15 & 27.50 & 42.00 & $0.110(.913)$ \\
\hline Kilo (kg) & 73 & 10.34 & 64.10 & 93.00 & 78.50 & 4.63 & 71.80 & 86.00 & $0.245(.806)$ \\
\hline $\begin{array}{l}\text { Dil } \\
\text { basacağının } \\
\text { ağız içinde } \\
\text { takılı kalma } \\
\text { süresi (dak) }\end{array}$ & 68.2 & 11.36 & & & & & & & 0.6 \\
\hline $\begin{array}{l}\text { Genel } \\
\text { anestezi } \\
\text { süresi (dak) }\end{array}$ & & & & & 75.1 & 12.13 & & & \\
\hline
\end{tabular}

Tablo 2. Preoperatif ve postoperatif dil kesit alanı $\left(\mathrm{TA}^{1}\right.$ ve $\left.\mathrm{TA}^{2}\right)$, dil ödemi $\left(\mathrm{TA}^{2}-\mathrm{TA}^{1}\right)$, dil basacağının ağı içinde takılı kalma süresi ve genel anestezi süresi açısından tonsillektomi ve kontrol gruplarının karşılaştırılması.

\begin{tabular}{|c|c|c|c|c|c|c|}
\hline \multirow[t]{2}{*}{ Parametre $\left(\mathrm{cm}^{2}\right)$} & \multicolumn{2}{|c|}{$\begin{array}{l}\text { Tonsillektomi grubu } \\
(\mathrm{n}=31)\end{array}$} & \multicolumn{2}{|c|}{$\begin{array}{l}\text { Kontrol grubu } \\
(\mathrm{n}=30)\end{array}$} & & \multirow[t]{2}{*}{ p } \\
\hline & Mean & SD & Mean & SD & & \\
\hline $\mathbf{T A}^{1}$ & 3.93 & 1.29 & 3.80 & 0.20 & 1.282 & 0.212 \\
\hline $\mathbf{T A}^{2}$ & 4.63 & 0.28 & 3.91 & 0.23 & 6.192 & $0.000^{* * * *}$ \\
\hline $\mathbf{T A}^{2}-\mathbf{T A}^{1}$ (Dil ödemi) & 0.73 & 0.26 & 0.11 & 0.07 & 6.622 & $0.000^{* * *}$ \\
\hline $\begin{array}{l}\text { Dil basacağının takulı } \\
\text { kalma süresi (dak) }\end{array}$ & 68.2 & 3.36 & & & & \\
\hline $\begin{array}{l}\text { Genel anestezi } \\
\text { süresi (dak) }\end{array}$ & & & 75.1 & 2.13 & 0.6 & \\
\hline
\end{tabular}

$* * *=\boldsymbol{p}<0.05$

TA: Dil kesit alanı (Tongue Area) 


\section{Tartışma}

Çalışmamızda, tonsillektomi grubundaki hastalarda USG ile dil kesit alanı artışı ve dil ödemi tespit edilirken, kontrol grubundaki hastalarda dil kesit alanları bakımından anlamlı değişiklik saptanmadı. Bu sonuç ile, tonsillektomi cerrahisi yapılan erişkin hastalarda, dil basacağ ve ağız açacağının dil üzerinde oluşturduğu yüksek basınca bağlı olarak dil ödeminin geliştiği submental USG ile gösterilmiştir. Bizim çalışmamızdaki hastalarda ortaya çıkan dil ödemi klinik olarak semptomatik olmamıştır. Ancak, mekanik nedenlere bağlı ortaya çıkan ve subakut submasif dil ödemi olarak tanımlanan bu kavram, çıplak gözle fark edilemez ve klinik olarak semptomatik olması ekstübasyondan sonraki ikinci saat ile 24 saat arasındaki zaman aralığında gerçekleşebilir $(2,11,12)$. Dolayısıyla, hasta ve klinisyen açısından olumsuz sonuçlara yol açabilecek önemli bir sorundur.

Tonsillektomi geçiren hastalarda postoperatif komplikasyonların çoğunun üst hava yolu obstrüksiyonuna bağlı olduğu gösterilmiştir. Brown ve ark. (13) tarafından yapılan bir çalışmada tonsillektomi sonrası ilk 1 saat içinde gelişmeyen ancak postoperatif 1-8 saat arasında gelişen solunum yolu komplikasyonlarının, toplam komplikasyonların üçte birini oluşturduğu gösterilmiştir. Dil basacağı ve ağız açacağının dil üzerinde uyguladığı yüksek basınca bağ 1 olarak gelişen dil ödeminin, Brown ve ark. (13) tarafindan gösterilen geç hava yolu komplikasyonlarıyla ilişkili olabileceğini düşünüyoruz.

Tonsillektomi cerrahisini yapan KBB klinisyen'i tarafından görüş alanını arttırmak için kullanılan dil basacağı ve ağız açacağının neden olduğu subakut submasif dil ödeminin tanısının ekstübasyondan önce USG ile konulmas1, üst hava yolu obstrüksiyonu ve postoperatif solunum komplikasyonlarını önlemek açısından önemlidir. Önal ve ark. $(11,12)$ tarafından yapılan iki farklı çalışmada, tonsillektomi ve adenoidektomi cerrahisi yapılan çocuk hastalarda ortaya çıkan dil ödemi USG ile saptanmış ve dil ödemi subakut dönemde ortaya çıktı̆̆ ve submasif karakterde olduğu için subakut submasif dil ödemi olarak adlandırılmıştır. Buna göre, subakut submasif dil ödemi kavramı, masif dil ödeminden farklı olarak hemen ortaya çıkmayan, ekstübasyondan sonra ikinci saat ile 24 saat arasında klinik belirti veren, çıplak gözle fark edilemeyen ancak USG ile tespit edilebilen dil ödemini tanımlamaktadır.

Obstruktif uyku apne sendromu (OUAS) hastalarında yapılan iki farklı çalışmada $(14,15)$ dil kalınlığı ve yüzey alanını ölçmek için USG kullanılmış ve elde edilen değerlerin ağır OUAS hastalarında OUAS olmayan hastalara göre daha yüksek olduğu saptanmıştır. Ancak aynı çalışmada, dil ölçülerindeki farklılıkların çıplak gözle fark edilemeyeceği belirtilmiştir. Çalışmamızda, subakut dönemde dil basacağının dile yaptığı basınca bağlı olarak dil kesit alanı artmış ve bu artış çıplak gözle fark edilemeyip USG ile tespit edilmiştir. Subakut dönemde meydana gelen dil ödemi her ne kadar submasif karakterde olsa bile, özellikle dar hava yolu geçişine sahip hastalarda trajik sonuçlara yol açabilmektedir. Dar hava yolu geçişinin, daha da kısıtlı hale gelmesine neden olan dil ödemi, ameliyat sonrası dönemde solunum sıkıntısına neden olabilir. Ayrıca tonsillektomi komplikasyonlarından biri olan erken dönem tonsil kanaması durumunda, hava yolu devamlılığı bozulmakta, dil ödeminin neden olduğu hava yolundaki daralma, hasta için yüksek morbidite ve mortaliteye neden olabilmektedir.

Süspansiyon laringoskopi işlemlerinde kullanılan süspansiyon kaşığının, dil üzerinde 10-30 dakika boyunca uyguladığı 1000 mmHg'lık basıncın, dilde iskemi-reperfüzyon hasarına ve dil ödemine neden olabileceği USG ile gösterilmiştir (16). Dil kasları ile benzer olan iskelet kaslarında yapılan çalışmalarda kritik iskemi süresinin, doku tipine bağlı olarak 3-4 saat olduğu tespit edilmiştir (17). İskelet kaslarındaki iskemi reperfüzyon hasarının araştırıldığı çalışmalarda, iskelet kaslarının periferik sinirlerinde, iskemiden 3 saat sonra başlayan ve en az yedi gün süren reperfüzyonun, iskeminin şiddetini arttırdığ 1 bilinmektedir (18). Reperfüzyonun başladığı ilk saatten yedinci güne kadar lipid peroksidasyonunun arttığı, endotel hücrelerinde endonöral ödem, ardından akson ve sinir liflerinde DNA hasarı ve nekrotik hücre ölümünün ortaya çıktığı gösterilmiştir. Ayrıca, ortaya çıkan ödem ve inflamasyondaki artışın, yüksek basınca bağlı ortaya çıkan iskemi-reperfüzyon hasarının sonucu olduğu da belirtilmiştir (19). Dil dokusunu inerve eden sinirlerde, yüksek basınca bağlı gelişmesi beklenen iskemi-reperfüzyon hasarının tespiti için, dil dokusunu inerve eden sinirlerin görüntüleme yöntemleri ile incelenmesi planlanabilir. İntraoral yerleşimli probu olan USG, deneyimli bir radyoloji uzmanı tarafından bunun için kullanılabilir.

Sonuç olarak, tonsillektomi cerrahisi yapılan erişkin hastalarda dil basacağının ve ağız açacağının dil üzerinde oluşturduğu basınca bağlı olarak subakut submasif dil ödemi gelişmektedir. Ekstübasyon sonrası subakut dönemde ortaya çıkan submasif dil ödemi, hava yolu geçişi zaten dar olan hastalarda, hava yolunun tamamen ya da kısmen kapanmasına neden olarak hasta tamamen uyanık olsa bile solunumsal komplikasyonların gelişmesine neden olabilir. Özellikle hava yolu geçişi dar olduğu bilinen riskli hasta grupları, tonsillektomi cerrahisi yapıldıktan sonra, ekstübe edilmeden önce, submental USG ile, subakut submasif dil ödemi açısından değerlendirilmeli ve geç dönemde ortaya çıkabilecek solunumsal komplikasyonlar açısından önlem alınmalıdır. Subakut submasif dil ödeminin ortaya çıkışı ve neden olduğu solunumsal komplikasyonlar ile ilgili, riskli hasta gruplarının dahil edildiği geniş popülasyonlu, prospektif, klinik çalışmaların yapılmasına ihtiyaç vardır.

\section{Referanslar}

1.Kundra P, Mishra SK, Ramesh A. Ultrasound of the airway. Indian J Anaesth. 2011;55(5):456-462

2.Onal M, Colpan B, Elsurer C, Bozkurt MK, Onal O, Turan A. Is it possible that direct rigid laryngoscope-related ischemia-reperfusion injury occurs in the tongue during suspension laryngoscopy as detected by ultrasonography: a prospective controlled study. Acta Otolaryngol. 2020;140(7):583-588

3.Lahav Y, Rosenzweig E, Heyman Z, Doljansky J, Green A, Dagan Y. Tongue base ultrasound: a diagnostic tool for predicting obstructive sleep apnea. Ann Otol Rhinol Laryngol. 2009;118(3):179-184

4.Abd-El-Malek S. Observations on the morphology of the human tongue. J Anat. 1939;73(Pt 2):201-210.3.

5.Abuan MRA, Lin WN, Hsin LJ, et al. Tongue imaging during drug-induced sleep ultrasound in obstructive sleep apnea patients. Auris Nasus Larynx. 2020;47(5):828-836

6.Yoshida H, Akizuki H, Michi K. Intraoral ultrasonic scanning as a diagnostic aid. J Craniomaxillofac Surg. 1987;15(6):306-311. doi:10.1016/s1010-5182(87)80076-8

7.Andruszkiewicz P, Wojtczak J, Sobczyk D, Stach O, Kowalik I. Effectiveness and Validity of Sonographic Upper Airway Evaluation to Predict Difficult Laryngoscopy. J Ultrasound Med. 2016;35(10):2243-2252

8.Tsui BC, Hui CM. Challenges in sublingual airway ultrasound interpretation. Can J 
Anaesth. 2009;56(5):393-394

9.Chan MT, Chan MS, Mui KS, Ho BP. Massive lingual swelling following palatoplasty. An unusual cause of upper airway obstruction. Anaesthesia. 1995;50(1):30-34.

10.Dell'Oste C, Savron F, Pelizzo G, Sarti A. Acute airway obstruction in an infant with Pierre Robin syndrome after palatoplasty. Acta Anaesthesiol Scand. 2004;48(6):787-789

11.Onal M, Colpan B, Elsurer C, et al. Can Tonsillar Retractor-Induced Tongue Edema Be a New Complication in Pediatric Patients Undergoing Tonsillectomy Detected by Ultrasonography? A Prospective, Case-Controlled, Observational Study [published online ahead of print, 2020 Jul 7]. Ear Nose Throat J. 2020;145561320934918.

12.Onal M. Assessment of tongue depressor-related tongue swelling in pediatric patients with ultrasonography: A prospective, case-controlled observational study. Medicine Science 2021;10(1):13-7

13.Brown KA, Morin I, Hickey C, Manoukian JJ, Nixon GM, Brouillette RT. Urgent adenotonsillectomy: an analysis of risk factors associated with postoperative respiratory morbidity. Anesthesiology. 2003;99(3):586-595

14.Santiago-Recuerda A, Gómez-Terreros FJ, Caballero P, et al. Relationship between the upper airway and obstructive sleep apnea-hypopnea syndrome in morbidly obese women [published correction appears in Obes Surg. 2007 Jul;17(7):996]. Obes Surg. 2007;17(5):689-697

15.Yamamoto H, Fujimura N, Namiki A. Masui. 2001;50(11):1250-1252.

16.Fang R, Chen H, Sun J. Analysis of pressure applied during microlaryngoscopy. Eur Arch Otorhinolaryngol. 2012;269(5):1471-1476

17.Gillani S, Cao J, Suzuki T, Hak DJ. The effect of ischemia reperfusion injury on skeletal muscle. Injury. 2012;43(6):670-675

18.Saray A, Can B, Akbiyik F, Askar I. Ischaemia-reperfusion injury of the peripheral nerve: An experimental study. Microsurgery. 1999;19(8):374-380.

19.Onal M, Elsurer C, Selimoglu N, et al. Ozone Prevents Cochlear Damage From Ischemia-Reperfusion Injury in Guinea Pigs. Artif Organs. 2017;41(8):744-752. 